\title{
A ANATOMIA HISTÓRICA DE GRAY: A REPRESENTAÇÃO DA ERA VITORIANA EM POOR THINGS, DE ALASDAIR GRAY
}

\section{GRAY'S HISTORICAL ANATOMY: THE REPRESENTATION OF THE VICTORIAN AGE IN ALASDAIR GRAY'S POOR THINGS}

\author{
Carolina de Pinho Santoro Lopes ${ }^{1}$
}

\begin{abstract}
RESUMO: Poor Things (1992), de Alasdair Gray, retoma a história de Frankenstein em uma paródia que se passa na cidade escocesa de Glasgow, durante a Era Vitoriana. O objetivo deste artigo é analisar a representação da Era Vitoriana no romance, enfocando principalmente questões sociais, políticas e econômicas. Além disso, pretende-se explorar a visão sobre a ciência na sociedade vitoriana, assim como o papel das mulheres nesse campo. Finalmente, será investigada a forma como a representação do século XIX contribui para a apresentação de críticas por parte de Gray sobre a época contemporânea.
\end{abstract}

PALAVRAS-CHAVE: ficção escocesa; história; Alasdair Gray; Era Vitoriana.

ABSTRACT: Set in Victorian Glasgow, Poor Things (1992), by Alasdair Gray, is a parody of Mary Shelley's Frankenstein. This work analyzes the representation of the Victorian Age in the novel, focusing especially on social, political and economic issues. Besides, the article explores Victorian society's view on science and the role of women in this field. Finally, the work deals with the way in which Alasdair Gray's representation of the $19^{\text {th }}$ century contributes to his criticism of contemporary times.

KEYWORDS: Scottish fiction; history; Alasdair Gray; Victorian Age.

A obra Frankenstein (1831), de Mary Shelley, vem dando origem a inúmeras adaptações e releituras desde a época de sua publicação. A figura da criatura que um humano trouxe à vida por meio de experimentos científicos foi muito além do romance original e povoa o imaginário das pessoas, apropriando-se inclusive do sobrenome de seu criador, Victor Frankenstein.

Poor Things (1992), de Alasdair Gray, é um exemplo de obra literária que retoma esse tema por meio de uma paródia na acepção que Linda Hutcheon dá ao termo (HUTCHEON, 2004, p. 125), pois ao mesmo tempo resgata e subverte o texto anterior. No romance de Gray, uma mulher bonita é reanimada por um médico de aparência grotesca, invertendo o enredo de Frankenstein. O nome do cientista, Godwin Bysshe Baxter, também reafirma a

\footnotetext{
${ }^{1}$ Doutoranda em Letras pela Universidade do Estado do Rio de Janeiro e professora do Colégio Pedro II.
} 
intertextualidade com a obra de Mary Shelley, uma vez que faz referência aos nomes do pai (William Godwin) e do marido (Percy Bysshe Shelley) da autora, além da família escocesa com quem ela viveu durante parte da juventude (Baxter). Alasdair Gray usa como cenário a cidade escocesa de Glasgow, durante a Era Vitoriana, aproveitando para tecer diversos comentários sobre o Reino Unido dessa época. O objetivo deste artigo é explorar a representação desse período histórico no romance, com foco especial na abordagem de questões sociais, políticas e econômicas, assim como na visão de ciência e do papel das mulheres nesse campo do conhecimento.

Alasdair Gray nasceu em Glasgow, em 1934, e trabalha como artista plástico e escritor. Ele costuma aliar seus interesses artísticos e literários, fazendo o desenho da capa e as ilustrações de vários de seus livros. O autor é conhecido por seu forte engajamento político como defensor do socialismo e da independência da Escócia, o que é exemplificado pelo livro Why Scots Should Rule Scotland (1992) e pelo panfleto How We Should Rule Ourselves (2005), ambos publicados em anos de eleição geral no Reino Unido.

Em Poor Things, Gray brinca com as fronteiras entre história e ficção ao se dizer apenas o editor de um manuscrito encontrado ao acaso. A obra é composta pela introdução assinada por Gray no papel de editor, seguida pelo relato de Archibald McCandless e uma carta de Victoria McCandless, que contradiz a narrativa anterior. A narrativa de Archibald gira em torno da reanimação de uma mulher que cometeu suicídio e da troca de seu cérebro com o do feto que ela carregava, o que dá origem a uma mulher de corpo adulto e mente infantil. Godwin Baxter, o médico que a traz de volta à vida, inventa uma origem plausível para ela e lhe dá o nome de Bella Baxter, afirmando ser uma sobrinha que ficou órfã fora do país. Depois de uma longa viagem que leva a seu amadurecimento, Bella acaba se casando com Archibald, o autor do relato, e descobre-se que o nome da mulher que foi ressuscitada era Victoria ${ }^{2}$.

A carta de Victoria McCandless, por sua vez, nega de forma veemente todos esses acontecimentos e atribui a escolha de seu marido de narrar sua história dessa forma à inveja que ele sentia de sua esposa e Godwin por não terem a mesma origem humilde que ele, assim como ciúmes da admiração e do amor que Victoria sentia por Godwin (GRAY, 2002, p. $273)^{3}$. Em sua introdução, Gray, fazendo uso do humor que permeia toda a obra, afirma acreditar no relato de Archibald e diz que escolheu colocar a carta como epílogo, pois assim

\footnotetext{
${ }^{2}$ Neste artigo, como nas notas de Gray ao final do livro, a personagem será chamada de Bella nas referências à narrativa de Archibald e Victoria ao tratar da carta escrita pela personagem.

${ }^{3}$ As referências ao romance serão feitas apenas pelo número da página daqui por diante.
} 
fica claro que se trata da narrativa de "uma mulher perturbada que quer esconder a verdade sobre o começo de sua vida" (p. xiii, tradução nossa) ${ }^{4}$.

Gray, o editor, usa diferentes estratégias para conferir legitimidade à narrativa de Archibald McCandless, o que contribui para tornar menos nítida a fronteira entre ficção e história. Em um relato de sua discussão com Michael Donnelly, o historiador que teria encontrado os textos publicados, Gray reforça a interface entre o papel do historiador e o do narrador, afirmando que já havia escrito ficção suficiente para reconhecer fatos históricos e que "tinha que tornar-[se] um historiador" para convencer Donnelly (p. xiii). São incluídas, então, na introdução, as datas exatas dos acontecimentos narrados por Archibald, junto com referências a diversos documentos comprobatórios. Quando Donnelly cobra dele as cópias dessas evidências, porém, Gray afirma ironicamente: "se meus leitores confiam em mim, não me importo com o que um 'especialista' pensa"6 (p. xvi), demonstrando um entrelaçamento entre história e ficção. Além disso, o Gray editor inclui notas críticas e históricas ao final do livro, em que apresenta mais detalhes e imagens relacionados às narrativas de Archibald e Victoria. Assim, de maneira bem-humorada, Alasdair Gray aponta para as similaridades de textos históricos e ficcionais, já que ambos tomam a forma de narrativas e são produzidos com base nas mesmas técnicas. Como afirma Hayden White, não é possível escrever a história sem narrativizá-la, já que é a estrutura narrativa que dá coerência a uma série de eventos (WHITE, 2006, p. 30).

Esse aspecto do romance leva alguns críticos a associarem a obra de Gray com o pósmodernismo. Brian McHale, por exemplo, considera que Alasdair Gray usa técnicas narrativas para revelar a ficcionalidade do que chamamos de mundo real (MILLER, 2005, p. 15). Para Donald P. Kaczvinsky, Poor Things questiona o ideal de objetividade histórica, podendo ser entendido como um exemplo de metaficção historiográfica (MILLER, 2005, p. 16). O conceito cunhado por Linda Hutcheon faz referência a romances que nos levam a "problematizar toda a questão do conhecimento histórico"7 (HUTCHEON, 1987, p. 285-286, tradução nossa). Para além dessas classificações, a literatura nos oferece formas de representação do passado que também são válidas. Hayden White argumenta que "a história não é menos uma forma de ficção do que o romance é uma forma de representação histórica" (WHITE, 1994, p. 138). Observar a seleção que Gray faz do que mostrar a respeito da Era

\footnotetext{
4 "a disturbed woman who wants to hide the truth about her start in life". Todas as traduções do romance serão de nossa autoria.

5 "I had to become a historian"

6 "if my readers trust me I do not care what an 'expert' thinks"

7 "novels that $[. .$.$] problematize the entire question of historical knowledge"$
} 
Vitoriana é importante para compreender a representação que o autor faz do período e dá subsídios para entender como esse retrato se relaciona com o contexto histórico e social da publicação de Poor Things.

\section{A desigualdade social}

Um aspecto da sociedade vitoriana enfatizado no romance é a desigualdade e a divisão em classes sociais. Essa questão pode ser percebida no relato de Archibald McCandless sobre suas origens e sua experiência na universidade. Filho de uma camponesa pobre com um homem que não o reconhecia como filho, Archibald sofria preconceito na faculdade de medicina por conta de seu jeito e de suas roupas, que deixavam claro o fato de que ele não tinha dinheiro e vinha do campo (p. 9). Um de seus professores chega a sugerir que ele deveria usar outras roupas e mudar seus modos, já que os pacientes e os outros médicos não confiariam nele por conta de sua aparência (p. 10), o que demonstra a preocupação vitoriana em parecer respeitável, além do preconceito em relação a outras classes sociais. Esse preconceito também está relacionado a aspectos linguísticos, uma vez que os colegas de Archibald riem dele por conta de seu sotaque do interior, que, segundo eles, não combinaria com discussões sérias sobre ciência (p. 16).

A rejeição às classes sociais mais baixas também pode ser percebida na descrição que Bella faz das imagens mostradas em Punch or The London Charivari, uma revista humorística publicada a partir do século XIX: “as [pessoas] mais feias e cômicas são os escoceses, irlandeses, estrangeiros, pobres, serviçais, os ricos que eram pobres até bem recentemente, homens pequenos, mulheres velhas solteiras e os socialistas"8 (p. 127). Esse trecho não só ilustra quais classes eram vítimas de maior preconceito, como também sugere que a divisão das classes não era só relacionada à riqueza, mas principalmente à ocupação e às origens de cada um. Sally Mitchell afirma que a classe social na Era Vitoriana era definida por fatores como a fonte de renda, a posição social da família e as conexões que ela possuía (MITCHELL, 2009, p. 34). O romance também aponta para a dificuldade de ascender socialmente no Reino Unido do século XIX. A mãe de Archibald, logo antes de morrer, deixa para o filho todas as suas economias e lhe diz para usar o dinheiro para se tornar alguém. Quando ele responde que se tornaria médico, a reação dela é "a careta cética com que reagia a

\footnotetext{
8 "The ugliest and most comical are Scots, Irish, foreign, poor, servants, rich folk who have been poor until very recently, small men, old unmarried women and Socialists."
} 
todas as sugestões estranhas" ${ }^{\prime 9}$ (p. 9), o que indica que a mobilidade social não era fácil.

A pobreza e a desigualdade são ligadas a questões políticas e econômicas no romance. As condições precárias em que os trabalhadores tinham que viver são associadas à necessidade de manter a produção industrial britânica em um preço competitivo em relação à dos outros países. Depois de Godwin ressaltar a importância de água limpa, uma dieta saudável e boas condições de habitação e trabalho para evitar doenças, Archibald responde que leis que diminuíssem os lucros das indústrias teriam efeitos catastróficos, uma vez que o Reino Unido importava muitos de seus alimentos (p. 24). Fica claro que boa parte da riqueza trazida pela Revolução Industrial estava limitada a uma pequena classe, não levando à melhoria das condições de vida de uma grande parcela da população.

O uso do poder político pelas elites para se manterem em posição privilegiada também é mencionado em Poor Things. De acordo com o relato de Archibald, durante sua longa viagem, Bella encontra um inglês, chamado Astley, que lhe explica assuntos políticos e econômicos. Ele descreve o Reino Unido como

uma terra onde os ricos usam decisões parlamentares para privar os pobres de seus lares e meios de sustento, onde rendas não provindas do trabalho crescem por meio de apostas na bolsa de valores, onde aqueles que possuem mais propriedades são os que trabalham menos e se divertem com a caça, as corridas de cavalos e levando seu país à guerra (p. 155). ${ }^{10}$

Segundo Astley, as pessoas são educadas para aceitarem essa realidade, uma vez que são ensinadas a admirar "assassinos e ladrões"11 como Aquiles e Ulisses; William, o Conquistador, e Henrique VIII (p. 155). Desse modo, a educação é vista como instrumento para convencer as pessoas a manterem o status quo, sendo o papel do ensino da história importante. Para White, o discurso histórico pode promover certos valores políticos e sociais (WHITE, 2006, p. 30), uma ideia que transparece no texto ficcional no trecho já citado.

Apesar de mostrar a condição de subalternidade a que eram submetidas as colônias britânicas, Gray deixa claro em seu romance que a desigualdade e a pobreza também estavam presentes na metrópole. De acordo com a narrativa de Archibald, o acontecimento que faz Bella perceber as mazelas do mundo onde vive ocorre em Alexandria, parte do Império Britânico na época. Nessa cidade, ao ver crianças pedindo dinheiro em frente a um hotel enquanto os hóspedes riem ou ficam indiferentes a elas, Bella tenta ajudar uma menina cega

\footnotetext{
9 "the sceptical grimace she made at all queer suggestions"

10 "a land where rich people use acts of parliament to deprive the poor of homes and livelihoods, where unearned incomes are increased by stock-exchange gambling, where those who own most work least and amuse themselves by hunting, horseracing and leading their country into battle"

11 "killers and stealers"
} 
que carrega um bebê, mas é impedida de levar as crianças com ela (p. 173). Essa experiência a choca e faz com que procure aprender mais sobre os problemas que assolam o mundo. Quando ela volta para Glasgow e diz a Godwin que eles devem retornar a Alexandria para ajudar os mais pobres, ele responde que não há necessidade de ir tão longe, pois é possível encontrar, em sua própria cidade, pessoas vivendo em péssimas condições e em áreas com grande incidência de doenças como a tuberculose e a disenteria (p. 196). Assim, o romance evidencia a pobreza e a desigualdade tanto nas colônias quanto dentro das ilhas britânicas.

Gray também demonstra diferentes formas, propostas na época, de lidar com esses problemas sociais. Por exemplo, para Astley, o homem de negócios inglês que Bella conhece durante a viagem, a pobreza ajuda a regular o tamanho da população. Segundo ele, o que o Reino Unido precisava eram mais cadeias e maior repressão policial e militar, além de abrigos com condições tão degradantes que as pessoas preferissem morrer a ficar neles: "foi assim que organizamos a nação industrial mais rica do mundo, e funciona muito bem"12 (p. 157-8). Assim, a pobreza não seria um problema a ser resolvido, mas parte integrante da estrutura social. Archibald McCandless, embora não compartilhe dessa opinião, também não se esforça para mudar essa situação. Victoria, em sua carta, afirma que o marido, após conseguir ascender e se tornar parte da classe média, não tinha o desejo de ajudar a classe trabalhadora a reformar a sociedade. Essa falta de empatia com a classe de que ele provinha também transparece na narrativa do próprio Archibald. Quando vai morar com Godwin, ele descreve as empregadas como pessoas que vieram da mesma classe que a mãe dele. No entanto, o máximo de consideração que ele demonstra em relação a elas é enviar "um buquê barato de flores ou um bilhete de agradecimento para a cozinha junto com os pratos sujos"13 (p. 72).

Victoria, por sua vez, buscava lutar contra os problemas sociais tanto por meio de sua atuação como médica quanto pelo engajamento político, com sua participação na Sociedade Fabiana, organização britânica fundada no fim do século XIX com o objetivo de estabelecer uma democracia socialista (p. 273). Victoria atribui as condições precárias de vida e trabalho dos mais pobres à manutenção do lucro das elites e faz uma forte crítica aos

lucros espremidos das vidas mirradas de crianças, mulheres e homens trabalhando mais de 12 horas por dia, seis dias por semana, em fábricas DESNECESSARIAMENTE imundas, uma vez que no século XIX já tínhamos conhecimento para fazer as coisas de maneira limpa. Não o utilizamos. Os lucros enormes da classe burguesa eram sagrados demais para serem questionados. (p. 275,

\footnotetext{
12 "That is how we have organized the world's richest industrial nation and it works very well"

13 "a cheap bunch of flowers or note of thanks down to the kitchen with the dirty plates"
} 
ênfase no original $)^{14}$

Essa avaliação da época é precedida por uma crítica à arquitetura vitoriana e seu custoso excesso de ornamentação. A opinião de Victoria parece ecoar os comentários de Alasdair Gray nas notas ao final do livro, pois o autor menciona os altos preços de duas construções erguidas durante o século XIX: a bolsa de valores de Glasgow e a escadaria de granito do West End Park (hoje chamado de Kelvingrove Park).

\section{O Império Britânico e correntes políticas}

Outro tema importante em Poor Things é o Império Britânico, com várias críticas à colonização ao longo do romance. O advogado Duncan Wedderburn, em uma carta supostamente escrita por ele e incluída no relato de Archibald, considera que Glasgow inventou o Império Britânico, pois a dominação de outros territórios dependeria do motor a vapor e do telégrafo e estaria baseada na teoria capitalista moderna. Esses três elementos foram inventados por pesquisadores ligados à Universidade de Glasgow - respectivamente, James Watt, William Thomson e Adam Smith. Wedderburn também compara o Império à Babilônia e relaciona ambos ao demônio por serem inteiramente materiais (p. 95-6). Apesar de ele ser representado como um homem mentalmente desequilibrado por Archibald, essa está longe de ser a única crítica ao imperialismo britânico na obra literária. Victoria, por exemplo, também o descreve como uma "pedra de moinho em torno de nossos pescoços"15 (p. 316).

No entanto, a colonização de outros territórios não é representada como uma exclusividade britânica. Astley afirma que todos os lugares densamente povoados tiveram seus impérios, a exemplo dos persas, dos gregos, dos chineses e dos espanhóis, dentre outros. Além disso, ele menciona que esse domínio militar é passageiro e que os imperialistas de uma época podem se tornar as colônias de outra (p. 160). Desse modo, a repetição de ciclos de ocupação de outros territórios por superpotências é enfatizada.

O romance também se refere ao fato de que o Reino Unido não era o único país com uma política imperialista. Em uma conversa com Dr. Hooker, um missionário americano que estava voltando da China, Astley lhe pergunta se a Câmara de Comércio ou o governo americano estavam pagando pela viagem. Hooker tenta se esquivar da pergunta, mas justifica sua presença na Ásia central - segundo ele, a maior área pagã ainda não dominada no mundo

\footnotetext{
14 "profits squeezed from the stunted lives of children, women and men working more than twelve hours a day, six days a week in NEEDLESSLY filthy factories; for by the nineteenth century we had the knowledge to make things cleanly. We did not use it. The huge profits of the owning classes were too sacred to be questioned." 15 "that millstone round our necks, the British Empire"
} 
- com o argumento de que o Reino Unido já havia tratado de dividir o resto do planeta, conquistando até mesmo colônias de outras potências (p. 137). Dessa forma, fica claro que outras nações industrializadas compartilhavam da intenção de dominar e explorar outros territórios. Além disso, a figura do missionário também demonstra que o projeto imperialista não estava restrito à dominação militar, mas incluía uma política de aculturação dos povos que viviam nessas regiões sob o pretexto de "civilizar" os nativos. Hooker demonstra descaso com relação à cultura chinesa, afirmando que o objetivo de sua visita não era aprender a língua chinesa, mas apenas ensinar ao povo "a língua e a fé da Bíblia cristã"16 (p. 131).

Dessa maneira, o romance expõe o uso da ideia de superioridade do colonizador para justificar a subjugação de outros povos. General Blessington, o primeiro marido de Bella, por exemplo, se refere às pessoas colonizadas como "selvagens" "17, demostrando esse sentimento de superioridade (p. 216). De acordo com Hooker, a conquista de territórios não deve ser encarada como uma guerra, pois "quando os britânicos invadem o Egito - quando os Estados Unidos interferem no México ou em Cuba -, eles estão mantendo a ordem e civilizando os nativos, e não lhes fazendo mal"18 (p. 141). O comentário seguinte do personagem - sobre como todos teriam paz e prosperidade até o ano 2000 graças à autoridade anglo-saxã - reforça a ironia usada por Gray e sua crítica ao discurso imperialista.

No entanto, o próprio Hooker reconhece que a colonização não acontecia por meios amigáveis, e sim por meio do poderio militar. Segundo ele, o que thes permite dominar "os líderes opressores das raças inferiores" são seus "rifles e metralhadoras e navios de guerra encouraçados e disciplina militar superior" ${ }^{\prime 19}$ (p. 140). Alasdair Gray sugere no romance que o tratamento dispensado aos povos colonizados era extremamente violento. Nas notas ao final da obra, Gray menciona um livro de memórias em que o Duque de Wellington descreve o fictício general Blessington da seguinte forma: “Aubrey é um soldado corajoso e inteligente, mas só se sente vivo ao matar pessoas. [...] Temos que mandá-lo para regiões tão distantes da Inglaterra quanto possível. Devemos mantê-lo lá"20 (p. 290). A citação ilustra como as vidas das pessoas oriundas das colônias eram consideradas menos importantes do que as dos ingleses. Em outra referência nas notas a uma fonte primária fictícia, Gray supostamente transcreve uma notícia de um jornal ilustrado narrando uma expedição do general Blessington

\footnotetext{
16 "the language and Faith of the Christian Bible"

17 "savages"

18 "When the British invade Egypt - when the States go into Mexico or Cuba - they are policing and civilizing the natives, not hurting them."

19 "the bullying rulers of the inferior races [...] [our] rifles and machine-guns and iron-clad warships and superior military discipline"

20 "Aubrey is a brave and clever soldier, but only feels alive when killing people. [...] We must send him to frontiers as far from England as possible. We should keep him there."
} 
para vingar o assassinato de um militar britânico cujo suspeito é o chefe de uma tribo indiana. A legenda da ilustração informa que foi encontrada uma "prova conclusiva de que o general Blessington tinha agido certo ao queimar as casas dos nativos culpados"21 (p. 298). Mais uma vez, Gray faz uso da ironia para criticar o imperialismo e a violência excessiva e gratuita contra os povos colonizados.

Outro jogo com verdade e ficção são as referências literárias ao general Blessington citadas nas notas no fim do livro. Uma das estratégias usadas por Gray é atribuir novos significados a obras literárias que de fato existem, afirmando, por exemplo, que o poema "The Eagle", de Alfred Tennyson, é um retrato do general, de quem o poeta teria sido amigo (p. 291). Um exemplo que mostra uma visão mais negativa do militar é a citação de um poema de Hilaire Belloc, “The Modern Traveller", que apresenta uma sátira anticolonialista. De acordo com Gray, Blessington teria inspirado o personagem capitão Blood (sangue), cujo nome é sugestivo de suas ações violentas, como no trecho do poema citado em Poor Things, que narra a supressão de uma revolta (p. 299). Outra estratégia de Gray é atribuir um texto criado por ele a outro autor, como o tributo fúnebre ao general supostamente escrito por Rudyard Kipling. Gozando de grande popularidade no século XIX, Kipling tratava de temas relativos ao Império de maneira laudatória, assegurando aos "seus compatriotas que a superioridade racial inglesa trazia a autoridade da lei a povos gratos em todos os lugares"22 (MITCHELL, 2009, p. 288, tradução nossa). O poema atribuído a Kipling no romance defende as ações do general e critica aqueles que reprovavam a violência empregada na colonização enquanto se beneficiavam dos ganhos comerciais trazidos por ela (p. 291-2). Desse modo, Gray não só expõe a hipocrisia de uma parcela da sociedade, mas também destaca o fato de que parte da riqueza do Reino Unido tem uma origem moralmente condenável.

A coexistência de diferentes correntes políticas é outro aspecto da sociedade vitoriana representado em Poor Things. Astley menciona uma série de pessoas que desejam distribuir as riquezas do mundo de forma igualitária. Ele aponta problemas em todos esses grupos, afirmando, por exemplo, que os comunistas tentariam se perpetuar no poder e seriam novos ditadores após uma revolução violenta ou que a eleição de socialistas para o parlamento não mudaria nada porque os legisladores trabalham com o objetivo de "proteger a própria riqueza E NADA MAIS"23 (p. 161-2, ênfase no original). Apesar disso, Bella se declara uma socialista (p. 164) e lista esses grupos como pessoas que melhoram o mundo ${ }^{24}$ (p. 161).

\footnotetext{
21 "conclusive proof that General Blessington had been right to burn the homes of the guilty tribesmen"

22 "his countrymen that English racial superiority brought the rule of the law to grateful peoples everywhere"

23 "to protect their wealth AND FOR NO OTHER REASON"

24 "WORLD IMPROVERS"
} 
Esse posicionamento político é corroborado pela carta de Victoria e pelas notas do editor a respeito dela, que também fazem referência a diversas figuras de destaque nesse campo na primeira metade do século XX. Victoria se identifica como membro da Sociedade Fabiana e demonstra conhecer o escritor H. G. Wells, que também pertenceu a essa organização (p. 273, 275-6). Nas notas ao fim do livro, Gray afirma que Victoria participou do movimento sufragista, lutando pelo direito de voto das mulheres, e que ela apoiava políticos socialistas que também se opunham à Primeira Guerra Mundial, como Keir Hardie e John Maclean (p. 305). Além disso, as notas também mostram que Victoria mantinha uma relação próxima com o poeta Hugh MacDiarmid, incluindo cartas entre os dois sobre assuntos políticos em que ela demonstra apoiar o Partido Trabalhista (pp. 312, 315). Dessa forma, a mistura entre figuras históricas e ficcionais contribui para a construção da personagem Victoria e a caracterização de seu engajamento político.

\section{As ciências naturais}

Além dessas questões políticas e econômicas, Gray aborda o papel da ciência em Poor Things. O estudo das ciências naturais ganhou prestígio e popularidade ao longo do século XIX devido à sua importância para o desenvolvimento industrial. Elas foram um elemento importante na formação da cultura da época e a visão otimista da ciência como algo ligado ao progresso vem, em grande parte, da época vitoriana (MORUS, 2004, p. 457-8). Alasdair Gray ironiza o destaque dado à ciência na passagem em que Archibald relata que começou a escrever poemas depois de se apaixonar por Bella. Archibald compara a imaginação ao apêndice por ser "herdada de uma época primitiva em que ajudava na sobrevivência da nossa espécie, mas que, nas nações industriais e científicas modernas, é principalmente uma fonte de doenças" ${ }^{25}$ (p. 55). Nessa analogia médica nada poética, é possível perceber uma crítica ao foco excessivo no desenvolvimento científico e industrial em detrimento do estímulo a um elemento essencial aos humanos como a imaginação.

A crescente popularização e importância da ciência na sociedade vitoriana pode ser observada nas diversas referências a cientistas ao longo do romance, além da inclusão, ao final de cada capítulo, de imagens do corpo humano retiradas do livro de anatomia de Henry Gray, publicado pela primeira vez no século XIX. Alguns cientistas mencionados viveram e trabalharam em Glasgow, como James Clerk Maxwell, William Thomson e James Watt (p.

\footnotetext{
25 "inherited from a primitive epoch when it aided the survival of our species, but in modern scientific industrial nations it is mainly a source of disease"
} 
16, 95, 261). As pesquisas de Thomson e Watt - que levaram, respectivamente, à criação do telégrafo e do motor a vapor - tiveram grande importância para o desenvolvimento industrial e econômico do Império Britânico. A única referência negativa a eles é a passagem mencionada antes em que Wedderburn, numa carta atribuída a ele por Archibald, critica o Império Britânico por ser excessivamente materialista (p. 95).

Godwin, por sua vez, considera que os trabalhos de Maxwell e Thomson sobre a eletricidade trazem descobertas sobre o que percorre nossos nervos e o cérebro (p. 16). No romance, outro exemplo de aplicação da eletricidade nos estudos sobre o corpo humano são os experimentos envolvendo descargas elétricas em cadáveres. De acordo com o médico do general Blessington, no relato de Archibald, conta-se até um caso em que um criminoso executado conseguiu se sentar e falar depois das descargas elétricas (p. 212-3). Embora nenhum tenha sido tão bem-sucedido quanto o personagem afirma, esses experimentos realmente foram feitos ao longo do século XIX, sendo inclusive uma possível inspiração para Mary Shelley ao escrever Frankenstein (TURNEY, 1998, p. 22).

Esse século também foi marcado pela abordagem mais preventiva na medicina, com a área de saúde pública ganhando destaque. Durante o período vitoriano, a conquista mais significativa no campo da medicina foi a criação de leis que estabelecessem medidas eficazes para melhoria da saúde pública (MITCHELL, 2009, p. 212). Godwin defende a importância de boas condições de moradia e saneamento, além de higiene pessoal e hábitos alimentares saudáveis para evitar doenças (p. 24). Em uma das passagens cômicas do romance, o médico compartilha um sonho adolescente com Archibald: após ler Hamlet, ele se imagina resolvendo os problemas da corte, atribuídos à febre tifoide, com o estabelecimento de uma quarentena e uma mudança no abastecimento de água do castelo, o que faria Ofélia se apaixonar por ele (p. 39-40). No entanto, fica claro que o conhecimento para evitar as doenças não era necessariamente colocado em prática. Como discutido antes, o romance demonstra que nem todos tinham acesso a condições dignas de moradia e trabalho. Como consequência, os problemas persistem, sendo Glasgow a cidade com a maior taxa de mortalidade infantil no Reino Unido na época, de acordo com Godwin (p. 34).

Poor Things também representa como as ciências naturais podem ter impacto sobre questões sociais. Dr. Hooker, o missionário que viaja com Bella, expressa em mais de uma cena do livro a ideia de que os povos anglo-saxônicos teriam cérebros maiores que os demais e, consequentemente, estariam destinados a dominar os outros e fazer com que controlassem seus instintos animais (p. 131, 139). Para Hooker, os britânicos e americanos são para os outros povos como "professores em um playground de crianças que não querem saber que a 
escola existe"26 (p. 139). Essa noção de determinismo biológico, isto é, de que as diferenças genéticas e étnicas determinam traços do intelecto, era frequentemente relacionada com a teoria da seleção natural de Darwin, dando origem à ideia de que alguns povos seriam mais aptos e fortes e, por isso, dominariam os demais. Essas teorias, muito em voga no século XIX, eram usadas como justificativa para as políticas de colonização de outros povos. Como as opiniões de Hooker são sempre recebidas com ironia ou descaso por Astley, pode-se perceber a rejeição dessa ideia de determinismo biológico no romance.

A obra também faz referência ao problema da poluição, ligado ao desenvolvimento tecnológico e industrial. Archibald comenta que duas semanas de sol tornavam Glasgow detestável por conta do acúmulo de gases e fumaça sobre a cidade. Além disso, os rejeitos químicos são despejados no rio, deixando a água turva, o que faz Archibald se perguntar se “os homens são os únicos animais terrestres que jogam excrementos na água" 27 (p. 44). Assim, o romance critica, além da desigualdade social mencionada anteriormente, outras consequências negativas da industrialização mais ligadas ao meio ambiente.

Fica claro, então, que a representação da ciência e da tecnologia em Poor Things não é idealizada ou excessivamente otimista. Dentro do relato de Archibald, há uma discussão entre ele e Godwin sobre o ato de reviver uma mulher morta após colocar nela o cérebro do feto que carregava. Godwin sente remorso por tê-la privado da infância apenas porque queria companhia e afirma que, independentemente do que os filantropos liberais possam afirmar,

as artes e as ciências não podem melhorar o mundo [...] Nossas novas e vastas habilidades científicas são usadas primeiro pelas partes abominavelmente gananciosas, egoístas e impacientes da nossa natureza e nação; a parte cuidadosa, bondosa e social sempre vem em segundo lugar (p. 68). ${ }^{28}$

A essa visão pessimista do potencial das novas descobertas científicas, Archibald responde que, como um apoiador do Partido Liberal, discorda de Godwin e acredita que a ciência possa contribuir para melhorias (p. 68). Considerando as diferentes questões apresentadas sobre o tema aqui, o conhecimento científico não é representado como intrinsecamente bom ou mau no romance, mas algo que tem a capacidade de trazer transformações tanto positivas quanto negativas. $\mathrm{O}$ impacto que a ciência causa na sociedade é, então, definido pela forma como as pessoas fazem uso dela.

\footnotetext{
26 "teachers in a playground of children who do not want to know that the school exists"

27 "men were the only land beasts who excreted into water"

28 "our arts and sciences cannot improve the world [...] Our vast new scientific skills are first used by the damnably greedy selfish impatient parts of our nature and nation, the careful kindly social part always comes second."
} 


\section{As mulheres na ciência e fora dela}

Outra questão relacionada à ciência que está presente no romance é a atuação das mulheres nesse campo de estudos, especialmente no que diz respeito à formação médica. De acordo com Morus, os cientistas do século XIX eram, em sua grande maioria, homens de classe média (MORUS, 2004, p. 458). Godwin acredita que a exclusão feminina do estudo da medicina leva à perda de muitas vidas (p. 66). Com essa opinião, o personagem se coloca em oposição à prática predominante na época, como é possível perceber pela afirmação que ele faz mais adiante de que existiam apenas quatro médicas no Reino Unido nesse período, todas formadas em universidades estrangeiras (p. 197). A dificuldade de acesso à educação enfrentada pelas mulheres começava antes da exclusão das universidades. Em sua narrativa, Victoria conta que sua mãe não a deixava ler porque "meninas não precisam de desculpas para o ócio" 29 (p. 256), demonstrando que as mulheres eram desestimuladas a perseguir os estudos. Ela também fala sobre a educação que recebeu em uma escola suíça, que não preparava as alunas para outros estudos ou para a atuação profissional, mas as ensinava a "ser o brinquedo doméstico de um homem rico"30 (p. 258-9). Sua escolha de palavras deixa evidente a crítica a uma educação feminina que só visava a tornar as mulheres mais atraentes dentro do mercado matrimonial.

Além dos problemas enfrentados pelas mulheres no acesso à educação e ao trabalho científico, Poor Things representa outros obstáculos e exemplos de discriminação impostos pelo patriarcado. Quando Godwin comenta que há um projeto de lei para permitir que mulheres casadas tenham direito a ter propriedades no seu nome, Archibald responde que o projeto nunca seria aprovado porque "enfraqueceria a instituição do casamento e a maioria dos parlamentares são maridos"31 (p. 67). Essa passagem reforça como a falta de representatividade política dificulta a criação de leis que garantam uma situação mais igualitária.

Outro exemplo de legislação prejudicial às mulheres abordado no romance é a lei do divórcio. O advogado do general Blessington afirma que o adultério masculino não é justificativa suficiente perante a lei para um divórcio e que Bella não conseguiria provar as alegações de maus tratos contra ela. Sendo assim, caso ela tentasse se divorciar com base nessas questões, acabaria sendo posta em custódia protetiva como incapaz (p. 234). Além

\footnotetext{
29 "Girls need no excuses for idleness"

30 "to be a rich man's domestic toy"

31 "It would undermine the institution of marriage and most M.P.s were husbands."
} 
disso, embora o general também se preocupe com o escândalo que o processo poderia causar, Bella teria que enfrentar ainda mais dificuldades, pois, como afirma Godwin, "um divórcio prejudicaria seriamente a carreira de uma mulher começando a trabalhar como médica na Escócia"32 (p. 239). Portanto, é possível observar que a sociedade vitoriana impunha restrições e exigências mais limitantes às mulheres que aos homens.

Em Poor Things, há a reversão dos papéis tipicamente atribuídos a cada gênero na Era Vitoriana, quando as expectativas e exigências eram que os homens trabalhassem e sustentassem a casa enquanto as mulheres se responsabilizariam pelo cuidado da família. Segundo Victoria, Archibald tem uma carreira medíocre, uma vez que só alcança uma posição importante pelos investimentos da família, e não por possuir uma mente brilhante, e fica apenas 11 meses nesse cargo (p. 251). Enquanto isso, o trabalho clínico de Victoria a mantém muito ocupada e exige até mesmo que ela trabalhe fora de Glasgow durante parte do ano, o que faz com que Archibald seja o responsável pela criação dos filhos do casal (p. 252). A respeito disso, Victoria afirma, de acordo com as notas de Gray, que "[seu] marido é uma esposa muito boa"33 (p. 303), enfatizando a ideia de inversão dos papéis de gênero esperados no século XIX. Essa inversão de papéis reforça a crítica presente no romance à desigualdade de gênero.

\section{A época contemporânea em Poor Things}

Embora a maior parte do romance se passe durante o século XIX, Alasdair Gray também insere comentários sobre acontecimentos históricos mais recentes. O período entre a década de 1970 - quando os relatos de Archibald e Victoria são supostamente encontrados até o princípio da década de 1990, época de publicação do romance, foi marcado por crises políticas e econômicas e pelas subsequentes transformações ocorridas durante o governo de Margaret Thatcher. Gray, com a sua ironia habitual, descreve a vida em Glasgow nos anos 1970 como "muito empolgante" ${ }^{34}$, enfatizando o processo de desindustrialização da cidade enquanto os governantes investiam em conjuntos habitacionais e rodovias (p. ix). Dessa maneira, Gray faz referência ao impacto do fechamento e da realocação das fábricas sobre a economia da cidade, que tinha se desenvolvido muito em função das indústrias, em especial da construção naval.

\footnotetext{
32 "a divorce would seriously injure the career of a woman doctor starting work in Scotland"

33 "I have a very good wife in my husband"

34 "very exciting"
} 
A esse cenário de desolação, Gray acrescenta uma representação de Glasgow como um lugar cuja história é vista com indiferença pelos governantes. Esse descaso pode ser observado, por exemplo, na afirmativa de que o museu sobre a história local, o People's Palace (Palácio do Povo), não recebia investimentos da prefeitura desde a Primeira Guerra Mundial, o que forçava seus funcionários a buscarem itens para a coleção em prédios que iam ser demolidos (p. ix). Essa busca por preciosidades descartadas é que leva Michael Donnelly, funcionário do museu, a encontrar, segundo Gray, as narrativas que compõem o romance. Outro exemplo desse desinteresse pelo passado é a transformação de um antigo prédio da Universidade de Glasgow em um condomínio de apartamentos luxuosos. Antes da reforma, Donnelly resgata desse prédio uma série de pinturas a óleo que seriam incineradas, não fosse pela intervenção dele (p. xii).

Além disso, o autor sugere no romance a contradição entre esse desinteresse pela conservação da história e a nomeação de Glasgow como Capital Europeia da Cultura em 1990. Gray conta que Donnelly deixa seu emprego no People's Palace nesse ano e coloca em dúvida se haverá contratação de algum substituto para ele (p. xii), o que sugere que o investimento em bens culturais não era uma prioridade do governo na visão do autor. Essa questão também está presente nos comentários de Gray sobre a fonte Stewart, erguida no século XIX em homenagem ao prefeito de Glasgow de mesmo nome. De acordo com Gray, a água da fonte foi desligada na década de 1970 e o monumento passou a ser usado como brinquedo pelas crianças, o que fez com que algumas esculturas quebrassem. Em 1989, a fonte foi restaurada e a água religada como preparação para a celebração da cidade como Capital da Cultura, mas o chafariz foi novamente desligado e cercado por um muro de madeira em 1992 (p. 284-5). Assim, o autor insinua que o investimento na cidade foi passageiro e não passou de uma fachada, não trazendo benefícios duradouros ou uma preocupação real com a conservação dos monumentos e da história local.

Gray também faz comentários negativos e irônicos a respeito dos Conservadores no romance. $\mathrm{O}$ autor faz referência a um costume antigo na Escócia de as crianças se reunirem em frente à casa de um casal prestes a se casar, esperando que o noivo jogue um punhado de moedas para elas. As crianças mais fortes e violentas, segundo ele, conseguiriam pegar o dinheiro enquanto as mais fracas teriam os dedos pisoteados e ficariam chorando. De acordo com Gray, esse costume ainda persiste em algumas áreas do país e seria considerado "um bom treinamento para o mundo da competição adulta" ${ }^{35}$ por alguns filósofos conservadores

\footnotetext{
35 "good training for the world of adult competition"
} 
modernos (p. 289). O comentário irônico sugere que Gray não compartilha da opinião dos teóricos conservadores e não as leva a sério.

O escritor ainda faz referência à campanha conservadora contra a reabertura do parlamento escocês que precedeu a eleição geral de 1992, incluindo a afirmação do presidente da companhia de seguros Scottish Widows de que a empresa se mudaria para a Inglaterra caso isso acontecesse (p. 285-6). De acordo com Alan McMunnigall, essa passagem pode explicitar o abuso de uma empresa voltada para o lucro contra uma nação subserviente, levando-se em conta que Gray é um socialista defensor da independência escocesa (MCMUNNIGALL, 2004, p. 337). O trecho também sugere um descontentamento de Gray com o tom de ameaça da campanha conservadora.

Passagens que tratam do contexto histórico do século XIX também podem trazer reflexões e comentários sobre o mundo contemporâneo. O Thatcherismo se caracteriza pela diminuição das regulamentações estatais, isto é, pelo papel reduzido do Estado e pela crença no livre mercado ${ }^{36}$. Em Poor Things, Astley afirma, sobre o comércio internacional na Era Vitoriana, que:

nosso parlamento definiu liberdade como a habilidade de comprar o mais barato possível e vender o mais caro possível em qualquer lugar, com a ajuda do exército e da marinha. Isso nos permite dividir países com a carestia tão facilmente quanto um carpinteiro corta madeira com uma serra (p. 159). ${ }^{37}$

Além de sugerir uma proximidade entre os contextos dos séculos XIX e XX, a citação demonstra uma visão crítica do comércio internacional desregulamentado, uma vez que deixa claro que os países mais poderosos têm grande vantagem e podem levar outras nações a graves crises.

No mundo contemporâneo, em um cenário de competição internacional acirrada, é necessário manter os preços de produção baixos para obter lucro, o que pode levar à transferência de fábricas e atividades produtivas de uma região para outra, causando a desindustrialização de áreas, a exemplo de Glasgow, como mencionado antes. Longe de ser novidade, no entanto, a estratégia de transferir a produção para áreas onde ela se tornaria mais barata é representada como algo já presente no período vitoriano no romance. Astley explica que, para conseguir competir com a Alemanha na fabricação de açúcar, sua empresa precisa

\footnotetext{
${ }^{36}$ What is Thatcherism? Disponível em: <www.bbc.com/news/uk-politics-22079683> Acesso em: 13 jul. 2017.

37 "our parliament has defined freedom as our ability to buy as cheap as possible and sell as dear as possible anywhere, with the help of our army and navy. This enables us to cut up countries with famines as readily as a carpenter cuts wood with a saw."
} 
da produção de "agricultores que trabalham por salários asiáticos, e não europeus" 38 (p. 136). Dessa forma, Gray retrata a atual tendência de realocar a produção para locais com mão de obra mais barata como um fenômeno que já acontecia no século XIX, assim como destaca a desigualdade entre trabalhadores de diferentes países.

As previsões dos personagens a respeito do futuro do Reino Unido também são uma forma de Gray tecer comentários a respeito do contexto de fins do século XX. Em uma das notas do editor, é incluída uma carta de Victoria para Hugh MacDiarmid em que ela comemora a vitória do Partido Trabalhista em 1945 e o fim das leis contra os sindicatos, afirmando que "parece que VAMOS conseguir o bem-estar social e um serviço de saúde nacional para todos, e Combustível e Energia e Transporte e Ferro e Aço VÃO se tornar Propriedade Pública!"39 (p. 316, ênfases no original). Considerando que Gray escreve o romance pouco depois do fim do governo de Thatcher, responsável pela privatização de uma série de estatais, a exemplo das companhias de gás e energia elétrica ${ }^{40}$, o elogio à nacionalização desses setores representa uma crítica do autor à política adotada durante a década de 1980.

Podemos concluir, então, que a representação que Alasdair Gray faz do contexto histórico em Poor Things contribui para uma crítica tanto de aspectos da sociedade vitoriana quanto do mundo contemporâneo. Ao enfatizar problemas relacionados à desigualdade social, ao imperialismo e à exclusão das mulheres durante o século XIX, o autor não só desconstrói a imagem da Era Vitoriana como uma época de ouro da história britânica, mas também aponta como as dificuldades enfrentadas em fins do século XX podem ter raízes no passado. Assim, o olhar crítico para o passado, em vez de distanciar, aproxima o leitor da realidade contemporânea e estimula uma reflexão sobre que futuro desejamos.

\section{REFERÊNCIAS:}

GRAY, Alasdair. Poor things. Londres: Bloomsbury, 2002.

HUTCHEON, Linda. A Poetics of postmodernism: history, theory, fiction. Londres:

Routledge, 2004.

HUTCHEON, Linda. The pastime of past time: fiction, history, historiographic metafiction.

GENRE, Durham, v. 20, n. 3-4, p. 285-305, Fall-Winter 1987.

MCMUNNIGALL, Alan. Alasdair Gray and postmodernism. Studies in Scottish literature, Columbia, v. 33, n. 1, p. 335-348, jan. 2004.

MILLER, Gavin. Alasdair Gray: the fiction of communion. Amsterdam (NY): Rodopi, 2005.

\footnotetext{
38 "farmers who work for Asiatic, not European wages"

39 "it seems we WILL get social welfare and national health care for all, and Fuel and Power and Transport and Iron and Steel WILL become Public Property!"

${ }^{40}$ What is Thatcherism? Disponível em: <www.bbc.com/news/uk-politics-22079683> Acesso em: 13 jul. 2017.
} 
MITCHELL, Sally. Daily life in Victorian England. Westport: Greenwood Press, 2009. MORUS, Iwan Rhys. The sciences. In: WILLIAMS, Chris (ed.). A companion to NineteenthCentury Britain. Oxford: Blackwell, 2004. p. 457-470.

TURNEY, Jon. Frankenstein's footsteps: science, genetics and popular culture. New Haven: Yale University Press, 1998.

WHAT is Thatcherism? Londres: 2013. Disponível em: $<$ http://www.bbc.com/news/ukpolitics-22079683>. Acesso em 13 de jul. de 2017.

WHITE, Hayden. Historical discourse and literary writing. In: KORHONEN, Kuisma (ed.). Tropes for the past: Hayden White and the History/Literature Debate. Amsterdam (NY):

Rodopi, 2006. p. 25-33.

WHITE, Hayden. Trópicos do discurso: Ensaios sobre a crítica da cultura. Tradução de Alipio Correia de Frarca Neto. São Paulo: EDUSP, 1994.

Recebido em 29/08/2018. Aceito em 24/10/2018. 